Buletin Ilmiah Math. Stat. dan Terapannya (Bimaster)

Volume 08, No. 2 (2019), hal 273 - 280.

\title{
PENERAPAN ALGORITMA MAX-MIN ANT SYSTEM DALAM PENYUSUNAN JADWAL MATA KULIAH DI JURUSAN MATEMATIKA FMIPA UNTAN
}

\author{
Qalbi Aliklas, Neva Satyahadewi, Hendra Perdana
}

\section{INTISARI}

\begin{abstract}
Penyusunan jadwal mata kuliah merupakan suatu permasalahan yang sering terjadi di suatu perguruan tinggi. Penjadwalan mata kuliah merupakan proses penyusunan jadwal pelaksanaan kuliah yang menginformasikan tempat belajar, waktu, mahasiswa yang mengambil serta dosen yang mengajar mata kuliah tersebut. Satu diantara metode untuk menyusun suatu jadwal yaitu Ant Colony Optimization. Ant Colony Optimization merupakan metode metaheuristik yang terinspirasi dari perilaku semut dalam menemukan rute menuju sumber makanan. Pada penelitian ini digunakan algoritma Max-Min Ant System untuk memperoleh jadwal mata kuliah yang optimal. Data jumlah mata kuliah, mahasiswa, ruangan, waktu dan sesi serta kapasitas ruang diinput kemudian diperoleh suatu jadwal mata kuliah yang optimal dengan menggunakan metode algoritma Max-Min Ant System.
\end{abstract}

Kata Kunci: Penjadwalan mata kuliah, Algoritma, Ant Colony Optimization

\section{PENDAHULUAN}

Proses perkuliahan yang berlangsung di setiap Universitas harus terstruktur agar dapat berjalan dengan lancar. Waktu dan tempat yang telah ditentukan untuk tiap mata kuliah berguna agar proses perkuliahan tidak terjadi bentrok. Oleh karena itu, setiap awal semester dilakukan proses penjadwalan mata kuliah. Penjadwalan ini mengatur waktu dan tempat untuk setiap mata kuliah yang berlangsung baik itu di semester ganjil ataupun genap.

Masalah utama penjadwalan adalah bagaimana menempatkan mata kuliah pada suatu waktu dan tempat [1]. Mahasiswa yang mengikuti proses perkuliahan juga harus dapat hadir pada setiap proses perkuliahan. Oleh karena itu, perlu adanya proses optimasi yang dapat diterapkan untuk menyelesaikan permasalahan penjadwalan mata kuliah di Program Studi (Prodi) Statistika Fakultas Matematika dan Ilmu Pengetahuan Alam (FMIPA) Universitas Tanjungpura (Untan). Sebagai acuan dalam pembuatan jadwal mata kuliah, perlu adanya penetapan suatu batasan dalam proses penjadwalan mata kuliah yang tidak boleh dilanggar (hard constraint) dan batasan yang boleh dilanggar (soft constraint) [1].

Proses pencarian solusi yang dapat digunakan adalah dengan menggunakan metaheuristics network yang satu diantaranya adalah Ant Colony Optimization (ACO). ACO adalah metode yang terinspirasi oleh perilaku semut dalam menemukan jalur dari koloninya menuju sumber makanan. Selama berjalan, setiap semut mengeluarkan pheromone yang merupakan alat komunikasi tak langsung dari koloni semut. Semut lainnya sensitif dengan pheromone tersebut sehingga akan mengikuti jejaknya. Proses ini membuat koloni semut menentukan jalur optimal menuju sumber makannya [2]. Permasalahan penjadwalan mata kuliah ini dapat diselesaikan dengan menggunakan ACO khususnya Algoritma Max-Min Ant System (MMAS).

Penelitian ini menerapkan konsep dan cara kerja algoritma MMAS untuk memperoleh jadwal mata kuliah yang optimal. Proses ini tidak memasukkan data mata kuliah minor dan hanya menjadwalkan mata kuliah yang menggunakan ruangan kelas. Proses penjadwalan mata kuliah dimulai dengan input data mata kuliah, jumlah ruangan, jumlah sesi, jumlah hari dan kapasitas ruang. Kemudian menentukan koordinat slot yang akan digunakan untuk menghitung jarak antar 
slot. Semut akan menghitung nilai peluang untuk memilih slot selanjutnya. Setelah semua slot dikunjungi dan tabulist menjadi penuh maka dihitung total jarak. Hanya semut dengan rute terbaik di setiap iterasi yang dapat mengupdate pheromone. Iterasi terus berjalan hingga terjadi konvergensi atau telah mencapai iterasi maksimal.

\section{PENJADWALAN}

Penjadwalan adalah penyusunan jadwal yang menyesuaikan dengan sejumlah batasan (constraint). Masalah penjadwalan dapat diselesaikan dengan menempatkan event pada satu time slot, sehingga memenuhi constraint yang telah ditentukan. Terdapat dua jenis constraint yang berfungsi sebagai pembatas suatu keluaran solusi yaitu hard constraint dan soft constraint [1]. Suatu jadwal dikatakan layak jika tidak melanggar hard constraint dan dikatakan optimal jika tidak melanggar soft constraint [3]. Hard constraint merupakan batasan yang bersifat tegas dan tidak boleh dilanggar. Berikut adalah hard constraint pada penjadwalan mata kuliah di Program Studi Statistika Jurusan Matematika FMIPA Untan, yaitu:

1. Ruangan yang tersedia adalah H1.1, H1.2 dan Laboratorium Komputer;

2. Kapasitas ruangan adalah sebagai berikut: H1.1 menampung 80 mahasiswa, H1.2 menampung 55 mahasiswa, dan Laboratorium Komputer menampung sebanyak 40 mahasiswa;

3. Sesi pagi (07.30-10.00) dan sesi sore (13.00-15.30) untuk mata kuliah 3 SKS dan sesi siang (10.15-11.55) untuk mata kuliah 2 SKS;

4. Jumlah mahasiswa disesuaikan dengan kapasitas ruangan;

5. Pada hari rabu, khusus sesi siang digunakan untuk rapat prodi sedangkan sesi siang pada hari jumat ditiadakan untuk waktu sholat jumat;

6. Dosen tidak boleh mengajar dua kelas dalam satu waktu.

Soft constraint adalah batasan yang masih boleh dilanggar. Artinya jika batasan ini dilanggar masih bisa diterima. Soft Constraint yang ditetapkan adalah sebagai berikut:

1. Alokasi jadwal kuliah mahasiswa semester pertama diusahakan mulai pada sesi pagi;

2. Mahasiswa diusahakan hanya memiliki dua mata kuliah dalam satu hari;

3. Dosen diusahakan tidak mengajar lebih dari dua sesi dalam satu hari.

\section{ANT COLONY OPTIMIZATION}

Ant Colony Optimization diperkenalkan oleh Moyson dan Manderick, namun secara meluas dikembangkan oleh Marco Dorigo. Metode ini terinspirasi oleh perilaku semut dalam menemukan jalur dari koloninya menuju sumber makanan. Semut menggunakan lingkungannya sebagai media komunikasi. Mereka bertukar informasi secara tidak langsung melalui pheromone. Informasi yang ditukar memiliki ruang lingkup lokal, dimana hanya seekor semut yang terletak di tempat pheromone itu berada dapat mengambil informasi. Proses peninggalan pheromone untuk bertukar informasi ini dinamakan stigmery [2].

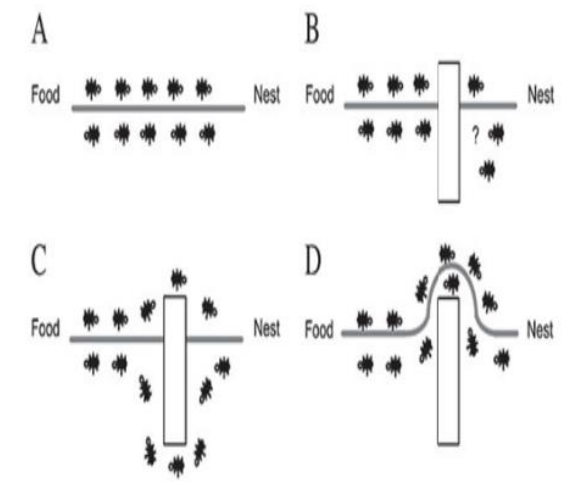

Gambar 1 Simulasi koloni semut mencari makanan [2] 
Penjelasan sistem kerja semut dalam mencari makanan berdasarkan Gambar 1 yaitu pada awalnya koloni semut berkeliling secara acak mencari sumber makanan. Ketika semut diberi hambatan menuju makanan, koloni semut tersebut harus menentukan arah yang akan dipilih. Kemudian koloni semut memilih jalan yang berbeda untuk menuju ke sumber makanan. Seiring waktu, jumlah semut yang melewati jalur lebih panjang mulai berkurang karena penguapan pheromone yang lebih cepat dibandingkan dengan jalur pendek. Akhirnya, semua koloni semut memilih jalur yang lebih pendek karena semut cenderung memilih jalur yang memiliki pheromone dengan konsentrasi tinggi.

\section{ALGORITMA MAX-MIN ANT SYSTEM}

Max-min Ant System (MMAS) merupakan pengembangan dari algoritma Ant System (AS) dengan beberapa perubahan utama [4]. Berikut tiga perubahan utama dalam MMAS terhadap AS:

1. Penambahan pheromone bisa dilakukan pada edge-edge yang merupakan bagian dari rute terbaik yang ditemukan sejak awal algoritma (best so-far tour) atau pada rute terbaik yang ditemukan pada iterasi tersebut (iteration best-tour). Penambahan pheromone juga bisa dilakukan sekaligus pada keduanya yaitu best so-far tour dan iteration best-tour sekaligus. Tetapi, strategi ini memungkinkan terjadinya stagnasi di awal pencarian yang menyebabkan semua semut melalui jalur yang sama. Hal ini dikarenakan pemberian pheromone yang berlebihan pada edge, meskipun bagian dari rute yang terbaik.

2. Mengatasi masalah pada perubahan pertama, maka MMAS memberikan batasan dalam pemberian nilai pheromone dengan selang $\left[\tau_{\min }, \tau_{\max }\right]$.

3. Pheromone diinisialisasi dengan batas maksimal nilai pheromone, dimana tingkat penguapan pheromone yang kecil akan meningkatkan eksplorasi rute sejak dimulainya pencarian.

\section{ATURAN TRANSISI STATUS}

Aturan transisi untuk semut $k$ yang berada pada slot $i$ akan memilih menuju ke slot $j$ dipilih berdasarkan distribusi peluang [5]. Persamaannya adalah sebagai berikut:

Keterangan:

$$
P_{i j}^{k}=\left\{\begin{array}{r}
\frac{\tau_{i j}^{\alpha} \eta_{i j}^{\beta}}{\sum_{c_{i l} \in N\left(s^{p}\right)} \tau_{i l}^{\alpha} \eta_{i l}^{\beta}}, \text { untuk } j \in N\left(s^{p}\right) \\
0, \text { untuk j lainnya }
\end{array}\right.
$$

$P_{i j}^{k} \quad$ : Peluang semut $k$ pada slot $i$ akan memilih menuju ke slot $j$.

$N\left(s^{p}\right)$ : Himpunan slot yang akan dikunjungi oleh semut $k$ yang sedang berada pada slot $i$.

$l \quad$ : slot yang belum dikunjungi oleh semut $k$

\section{PERHITUNGAN PANJANG RUTE}

Perhitungan panjang rute setiap semut dilakukan setelah setiap semut menyelesaikan rutenya masing-masing [3]. Perhitungan panjang rute semut $k$ dilakukan berdasarkan $t a b u_{k}$ dengan persamaan sebagai berikut.

$$
C^{k}=d^{k}{ }_{t a b u(n), t a b u(1)}+\sum_{j=1}^{n-1} d^{k} \operatorname{tabu(j),tabu(j+1)}
$$

Keterangan:

$$
\begin{array}{ll}
d^{k}{ }_{\text {tabu }(j), t a b u(j+1)} & : \text { Jarak dari slot } j \text { sampai slot }(j+1) \text { pada tabulist yang ditempati oleh } \\
& \text { semut } k . \\
d^{k}{ }_{\text {tabu(n),tabu(1) }} & : \text { Jarak antara slot } n \text { (slot akhir) dengan slot pertama pada tabulist yang } \\
& \text { ditempati oleh semut } k \\
C^{k} & : \text { Panjang rute yang dilalui oleh semut } k
\end{array}
$$




\section{UPDATE PHEROMONE}

Algoritma MMAS hanya memperbolehkan satu semut yang digunakan untuk update pheromone setelah setiap iterasi dilakukan [4]. Aturan update pheromone algoritma MMAS diberikan sebagai berikut.

$$
\begin{gathered}
\tau_{i j}(t+1)=(1-\rho) \tau_{i j}(t)+\Delta \tau_{i j}^{b e s t} \\
\Delta \tau_{i j}^{b e s t}=\frac{1}{C^{i b}}
\end{gathered}
$$

Keterangan:

$$
\begin{array}{ll}
C^{i b} & \text { : Panjang rute terbaik pada setiap iterasi } \\
\rho & \text { : Tetapan penguapan pheromone yang berada pada selang }[0,1] \\
t & \text { : Banyaknya iterasi }
\end{array}
$$

Selanjutnya update pheromone dibatasi dengan mengikuti aturan sebagai berikut [4]:

$$
\begin{aligned}
& \tau_{i j}=\left\{\begin{array}{rr}
\tau_{\min }, \text { jika } \tau_{i, j}<\tau_{\min } \\
\tau_{\max }, \text { jika } \tau_{i, j}>\tau_{\max } \\
\tau_{i, j}, \text { lainnya. }
\end{array}\right. \\
& \tau_{\max }=\frac{1}{\rho C^{i b}} \\
& \tau_{\min }=\frac{\tau_{\max }\left(1-\sqrt[n]{p_{\text {best }}}\right)}{\left((\operatorname{avg}-1) \sqrt[n]{p_{\text {best }}}\right)}
\end{aligned}
$$

Keterangan:

$\tau_{\max }:$ Batas maksimal pemberian pheromone

$\tau_{\min }:$ Batas minimal pemberian pheromone

avg : Jumlah slot dibagi 2

Setelah menyelesaikan rute dan menghitung panjang rute yang dilalui. Semut akan meninggalkan pheromone pada lintasan yang dilaluinya. Karena penambahan pheromone hanya boleh dilakukan oleh semut dengan panjang rute terbaik di setiap iterasi, maka akan menyebabkan terjadinya perubahan intensitas pheromone antar slot sehingga rute dengan jumlah pheromone yang lebih tinggi akan cenderung dipilih.

\section{PENETAPAN PARAMETER ALGORITMA}

Inisialisasi nilai parameter-parameter dalam penyelesaian program dengan menggunakan Algoritma MMAS, yaitu:

a. Intensitas pheromone antar slot dan update pheromone $\left(\tau_{i j}\right)$. Nilai pheromone awal diinisialisasi dengan $\tau_{\text {max }}$. Rumus $\tau_{\text {max }}$ dapat dihitung dengan Persamaan (5).

b. Banyaknya slot $(n)$ dan juga koordinat slot $(x, y)$. Rumus mencari jarak antar slot $\left(d_{i j}\right)$ yaitu $d_{i j}=\sqrt{\left(x_{i}-x_{j}\right)^{2}+\left(y_{i}-y_{j}\right)^{2}}, i$ adalah slot saat ini dan $j$ adalah slot selanjutnya.

c. Slot awal dan slot akhir adalah sama.

d. Tetapan pengendali intensitas jejak semut $(\alpha>0)$. Parameter yang mengontrol bobot (weight) relatif dari pheromone.

e. Parameter pengendali jarak $(\beta>0)$.

f. Invers jarak antar slot $\left(\eta_{i j}=\frac{1}{d_{i j}}\right)$.

g. Banyaknya semut $(m)$.

h. Tetapan penguapan pheromone $(\rho)$, nilainya $0<\rho \leq 1$. Hal ini untuk mencegah jumlah pheromone yang berlebihan.

i. Jumlah iterasi maksimum $\left(N C_{\max }\right)$, ditetapkan iterasi maksimum sebesar 1000 iterasi.

j. Panjang rute semut $\left(C^{k}\right)$. Panjang rute terbaik pada setiap iterasi $\left(C^{i b}\right)$. 
k. Batasan pemberian nilai pheromone dengan selang $\left[\tau_{\min }, \tau_{\text {max }}\right]$.

1. Peluang ditemukannya solusi terbaik $\left(p_{\text {best }}\right)$.

\section{PENERAPAN ALGORITMA MAX-MIN ANT SYSTEM}

Penyelesaian permasalahan penjadwalan mata kuliah dengan menggunakan algoritma MMAS untuk menentukan slot dalam bentuk penjadwalan. Program algoritma MMAS ini menggunakan kasus penjadwalan mata kuliah pada sistem perkuliahan di Prodi Statistika FMIPA Untan Tahun Ajaran 2018/2019 Semester Ganjil. Rincian informasi mata kuliah yang akan dibuat penjadwalan mata kuliah dapat dilihat pada Tabel 1.

Tabel 1 Rincian Informasi Mata Kuliah

\begin{tabular}{|c|l|c|c|c|c|c|}
\hline No & \multicolumn{1}{|c|}{ Mata Kuliah } & $\begin{array}{c}\text { Kode } \\
\text { Makul }\end{array}$ & Sem & SKS & $\begin{array}{c}\text { Jumlah } \\
\text { Mhs }\end{array}$ & $\begin{array}{c}\text { Kode } \\
\text { Dosen }\end{array}$ \\
\hline 1 & Analisis Data Eksploratif & ADE & 1 & 3 & 60 & NN \\
\hline 2 & Aljabar Matriks dan Vektor & AMV & 1 & 3 & 60 & FF + NI \\
\hline 3 & Matematika & MAT & 1 & 3 & 59 & MK + FF \\
\hline 4 & Fisika & FIS & 1 & 3 & 74 & MKDU \\
\hline 5 & Pengenalan Teknologi Informasi & PTI & 1 & 2 & 59 & MKDU \\
\hline 6 & Kimia Kontekstual & KK & 1 & 2 & 59 & MKDU \\
\hline 7 & Biologi Kontekstual & BK & 1 & 2 & 60 & MKDU \\
\hline 8 & Bahasa Inggris & BING & 1 & 3 & 59 & MKDU \\
\hline 9 & Kewarganegaraan & KWN & 3 & 2 & 50 & MKDU \\
\hline 10 & Analisis Regresi & AR & 3 & 3 & 51 & NN \\
\hline 11 & Riset Operasi & RO & 3 & 3 & 35 & MA \\
\hline 12 & Basis Data & KL & 3 & 3 & 49 & HP \\
\hline 13 & Kalkulus Lanjut & & & & & MK + \\
& & MN & 3 & 3 & 27 & SWR + \\
\hline 14 & Metode Numerik & & & & & YUD \\
\hline & & PSM I & 3 & 3 & 63 & NS + SWR \\
\hline 15 & Pengantar Statistika Matematika I & ALS & 3 & 3 & 57 & NI \\
\hline 16 & Aljabar Linear Statistika & SNP & 3 & 2 & 54 & H \\
\hline 17 & Statistik Non Parametrik & BIND & 5 & 2 & 37 & MKDU \\
\hline 18 & Bahasa Indonesia & MDW I & 5 & 3 & 44 & YUN + \\
\hline 19 & Metode Deret Waktu I & PSKU & 5 & 3 & 46 & ES \\
\hline & & KOMS & 5 & 3 & 42 & HP \\
\hline 20 & Pengantar Statistika Keuangan & 5 & 3 & 38 & HP + NS \\
\hline 21 & Komputasi Statistika & 5 & 3 & 43 & DK \\
\hline 22 & Matematika Aktuaria II & 7 & 3 & 37 & NI \\
\hline 23 & Ekonometrika & 7 & 3 & 18 & SWR \\
\hline 24 & Pengenalan Pengendalian Kualitas Statistika & PPKS & & & & \\
\hline 25 & Teori Bunga & & & & \\
\hline & & & & & \\
\hline
\end{tabular}

Berdasarkan Tabel 1, total slot yang dibutuhkan untuk penjadwalan mata kuliah adalah sebanyak 25 slot. Jumlah ruangan yang disediakan ada 3. Pembagian waktu atau sesi perkuliahan dibagi menjadi 3 sesi yaitu sesi pagi (07.30 - 10.00), sesi siang (10.15-11.55) dan sesi sore (13.00-15.30). Sesi siang dialokasikan untuk mata kuliah 2 sks karena mempertimbangkan waktu istirahat dan sholat zuhur. Kemudian alokasi hari yang tersedia adalah hari kerja (senin-jumat). Berdasarkan ketentuan tersebut maka total slot yang tersedia adalah sebanyak $3 \times 3 \times 5=45$ slot. 


\section{INISIALISASI PARAMETER AWAL}

Penyelesaian proses penjadwalan diawali dengan inisialisasi jumlah slot. Slot kemudian ditempatkan di koordinat kartesius secara acak agar dapat dihitung jarak antar slot. Selanjutnya diinisialisasi parameter awal untuk proses iterasi dalam pencarian rute terbaik. Nilai yang digunakan adalah $\alpha=1$, $\beta=2$. Nilai pheromone awal ditentukan dengan menginisialisasi $\tau_{\max }$ yang dapat dihitung setelah dapat rute awal. Nilai eta awal diperoleh dengan invers jarak antar slot. Inisialisasi parameter rho sebesar 0.02 dan $p \_$best sebesar 0.05 [4]. Iterasi maksimal ditetapkan sebesar 1000 iterasi.

Banyaknya semut yang digunakan adalah 100 semut. Semut kemudian ditempatkan secara acak pada slot yang sudah ditentukan. Kemudian rute awal didapatkan dengan random permutasi sehingga tidak ada slot yang akan terpilih kembali. Setelah didapat rute awal yang terbaik maka didapat nilai $\tau_{\min }$ dan $\tau_{\max }$ yang mana nilai $\tau_{\max }$ akan digunakan untuk inisialisasi pheromone awal. Selanjutnya, proses iterasi berlangsung untuk terus mencari rute yang optimal. Peluang slot-slot yang akan dikunjungi oleh semut dari slot sekarang yang sedang ditempati dihitung dengan menggunakan Persamaan (1). Proses perhitungan tersebut diulang sampai semua slot sudah dikunjungi hingga membentuk sebuah rute baru. Setelah itu dihitung jarak rute yang terbentuk agar didapat rute terbaik. Rute terbaik ini yang dipakai untuk meng-update pheromone sementara rute yang lain mengalami penguapan pheromone. Besarnya penambahan dan penguapan pheromone dihitung berdasarkan Persamaan (3).

Proses iterasi ini diulang sampai jumlah iterasi maksimum yang ditentukan atau jika sudah terjadi konvergensi. Hasil akhir dari penelitian ini adalah menampilkan rute terbaik yang dihasilkan dan jadwal mata kuliah Prodi Statistika Jurusan Matematika FMIPA Untan.

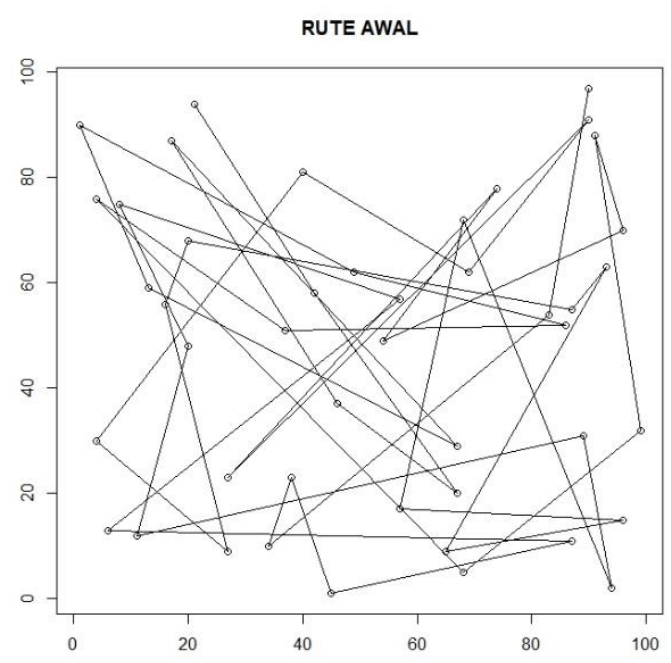

(a)

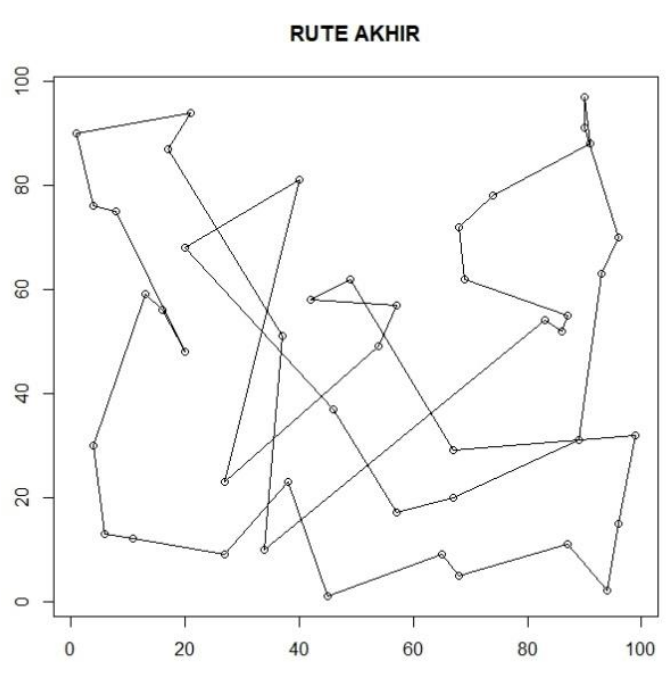

(b)

Gambar 2 Output rute awal dan rute akhir

Rute awal yang terbentuk dari algoritma MMAS berdasarkan Gambar 2 (a) adalah sebagai berikut.

$$
\begin{aligned}
& 5 \rightarrow 1 \rightarrow 12 \rightarrow 18 \rightarrow 3 \rightarrow 16 \rightarrow 11 \rightarrow 29 \rightarrow 2 \rightarrow 6 \rightarrow 10 \rightarrow 7 \rightarrow 31 \rightarrow 15 \rightarrow 17 \rightarrow 30 \rightarrow \\
& 26 \rightarrow 38 \rightarrow 24 \rightarrow 37 \rightarrow 27 \rightarrow 44 \rightarrow 13 \rightarrow 4 \rightarrow 21 \rightarrow 42 \rightarrow 39 \rightarrow 25 \rightarrow 14 \rightarrow 33 \rightarrow 40 \rightarrow \\
& 43 \rightarrow 45 \rightarrow 23 \rightarrow 34 \rightarrow 8 \rightarrow 32 \rightarrow 19 \rightarrow 22 \rightarrow 35 \rightarrow 20 \rightarrow 36 \rightarrow 9 \rightarrow 28 \rightarrow 41 \rightarrow 5
\end{aligned}
$$

Rute terbaik yang terbentuk dari algoritma MMAS berdasarkan Gambar 2 (b) adalah sebagai berikut. 


$$
\begin{aligned}
& 45 \rightarrow 23 \rightarrow 6 \rightarrow 28 \rightarrow 39 \rightarrow 25 \rightarrow 30 \rightarrow 43 \rightarrow 27 \rightarrow 12 \rightarrow 31 \rightarrow 14 \rightarrow 20 \rightarrow 36 \rightarrow 18 \rightarrow \\
& 1 \rightarrow 2 \rightarrow 26 \rightarrow 10 \rightarrow 8 \rightarrow 21 \rightarrow 11 \rightarrow 7 \rightarrow 29 \rightarrow 5 \rightarrow 3 \rightarrow 32 \rightarrow 42 \rightarrow 13 \rightarrow 34 \rightarrow 22 \rightarrow \\
& 9 \rightarrow 24 \rightarrow 4 \rightarrow 40 \rightarrow 16 \rightarrow 33 \rightarrow 35 \rightarrow 44 \rightarrow 19 \rightarrow 37 \rightarrow 17 \rightarrow 41 \rightarrow 38 \rightarrow 15 \rightarrow 45
\end{aligned}
$$

Urutan mata kuliah yang akan diinput kedalam slot sesuai dengan rute terbaik yang dihasilkan oleh algoritma MMAS. Namun dalam proses penempatan mata kuliah harus memperhatikan hard dan soft constraint yang telah ditetapkan sehingga didapat hasil penjadwalan mata kuliah Prodi Statistika

\begin{tabular}{|c|c|c|c|c|c|c|c|c|c|c|c|}
\hline RUANG & SESI & \multicolumn{2}{|c|}{ SENIN } & \multicolumn{2}{|c|}{ SELASA } & \multicolumn{2}{|c|}{ RABU } & \multicolumn{2}{|c|}{ KAMIS } & \multicolumn{2}{|c|}{ JUMAT } \\
\hline \multirow{6}{*}{$\begin{array}{c}\text { H1.1 } \\
\text { (Kapasitas } \\
\text { Maksimal } \\
\text { 80 Mhs) }\end{array}$} & 07.30 & \multicolumn{2}{|c|}{ Matematika } & & & \multicolumn{2}{|c|}{ Bahasa Inggris } & \multicolumn{2}{|c|}{ Aljabar Linear Stat } & \multicolumn{2}{|c|}{ Fisika } \\
\hline & 10.00 & Sem 1 & $\mathrm{MK}+\mathrm{FF}$ & & & Sem 1 & MKDU & Sem 3 & NI & Sem 1 & MKDU \\
\hline & \multirow{2}{*}{$\begin{array}{c}10.15 \\
- \\
11.55\end{array}$} & \multicolumn{2}{|c|}{$\begin{array}{l}\text { Peng. Teknologi } \\
\text { Informasi }\end{array}$} & \multicolumn{2}{|c|}{$\begin{array}{c}\text { Kimia } \\
\text { Kontekstual }\end{array}$} & \multirow{2}{*}{\multicolumn{2}{|c|}{ Rapat Prodi }} & \multicolumn{2}{|c|}{ Biologi Kontekstual } & & \\
\hline & & Sem 1 & MKDU & Sem 1 & MKDU & & & Sem 1 & MKDU & & \\
\hline & \multirow{2}{*}{$\begin{array}{c}13.00 \\
- \\
15.30\end{array}$} & & & \multicolumn{2}{|c|}{$\begin{array}{c}\text { Analisis Data } \\
\text { Eksploratif }\end{array}$} & \multicolumn{2}{|c|}{ PSM I } & \multicolumn{2}{|c|}{$\begin{array}{l}\text { Aljabar Matriks } \\
\text { Vektor }\end{array}$} & & \\
\hline & & & & Sem 1 & $\mathrm{NN}$ & Sem 3 & $\begin{array}{c}\mathrm{NS}+\mathrm{S} \\
\mathrm{WR}\end{array}$ & Sem 1 & $\mathrm{FF}+\mathrm{NI}$ & & \\
\hline RUANG & SESI & \multicolumn{2}{|c|}{ SENIN } & \multicolumn{2}{|c|}{ SELASA } & \multicolumn{2}{|c|}{ RABU } & \multicolumn{2}{|c|}{ KAMIS } & \multicolumn{2}{|c|}{ JUMAT } \\
\hline \multirow{6}{*}{$\begin{array}{c}\text { H1.2 } \\
\text { (Kapasitas } \\
\text { Maksimal } \\
\text { 55 Mhs) }\end{array}$} & \multirow{2}{*}{$\begin{array}{c}07.30 \\
- \\
10.00\end{array}$} & \multicolumn{2}{|c|}{ Ekonometrika } & & & & & & & $\begin{array}{r}\text { Pengan } \\
\mathrm{Ke}\end{array}$ & $\begin{array}{l}\text { tatistika } \\
\text { gan }\end{array}$ \\
\hline & & Sem 5 & DK & & & & & & & Sem 5 & ES \\
\hline & \multirow{2}{*}{$\begin{array}{c}10.15 \\
- \\
11.55\end{array}$} & \multicolumn{2}{|c|}{ Kewarganegaraan } & \multicolumn{2}{|c|}{ Kalkulus Lanjut } & \multirow{2}{*}{\multicolumn{2}{|c|}{ Rapat Prodi }} & \multicolumn{2}{|c|}{ Stat. Nonparametrik } & & \\
\hline & & Sem 3 & MKDU & Sem 3 & $\begin{array}{c}\mathrm{MK}+\mathrm{W} \\
\mathrm{BP}\end{array}$ & & & Sem 3 & $\mathrm{H}$ & & \\
\hline & 13.00 & & $\begin{array}{l}\text { putasi } \\
\text { istika }\end{array}$ & & W I & Analis & Regresi & & & & \\
\hline & 15.30 & Sem 5 & $\mathrm{HP}$ & Sem 5 & $\begin{array}{c}\text { YUN+ } \\
\text { SM }\end{array}$ & Sem 3 & NN & & & Sem 3 & $\mathrm{HP}$ \\
\hline RUANG & SESI & & NIN & & ASA & & & & MIS & & \\
\hline & 07.30 & Metod & Numerik & $\begin{array}{l}\text { Mat } \\
\text { Akt }\end{array}$ & $\begin{array}{l}\text { natika } \\
\text { aria II }\end{array}$ & & & & & Teo & Inga \\
\hline & 10.00 & Sem 3 & $\begin{array}{c}\text { SWR+Y } \\
\text { UD }\end{array}$ & Sem 5 & $\mathrm{HP}+\mathrm{NS}$ & & & & & Sem 7 & SWR \\
\hline Lab & 10.15 & & & & & & & B. I & onesia & & \\
\hline Maksimal & 11.55 & & & & & & & Sem 5 & MKDU & & \\
\hline $40 \mathrm{Mhs})$ & $\begin{array}{c}13.00 \\
- \\
15.30\end{array}$ & & & $\begin{array}{r}\mathrm{F} \\
\text { Peng } \\
\mathrm{K} \\
\text { Sta }\end{array}$ & $\begin{array}{l}\text { ng. } \\
\text { dalian } \\
\text { litas } \\
\text { stika }\end{array}$ & & & & & Rise & erasi \\
\hline & & & & Sem 7 & NI & & & & & Sem 3 & MA \\
\hline
\end{tabular}
Jurusan Matematika FMIPA Untan.

Tabel 2 Output penjadwalan mata kuliah menggunakan algoritma MMAS 
Tabel 2 merupakan hasil dari program penjadwalan mata kuliah menggunakan algoritma MMAS. Jadwal yang dihasilkan ini dapat digunakan karena tidak melanggar hard constraint dan soft constraint. Jadwal tersebut telah mengalokasikan waktu untuk rapat Prodi, sholat Jumat dan setiap mahasiswa hanya memiliki dua mata kuliah perhari di setiap semesternya.

\section{PENUTUP}

Algoritma MMAS merupakan pengembangan dari algoritma AS. Algoritma ini hanya memperbolehkan update pheromone pada rute terbaik di setiap iterasi dengan batasan pemberian pheromone $\left[\tau_{\text {min }}, \tau_{\text {max }}\right]$. Algoritma MMAS dapat memberikan solusi untuk masalah penjadwalan mata kuliah. Hard constraint dan soft constraint yang ditetapkan terlebih dahulu menjadi acuan dalam penyusunan jadwal mata kuliah. Penjadwalan mata kuliah menggunakan algoritma MMAS didapatkan hasil yang sesuai karena tidak melanggar hard constraint dan soft constraint.

\section{DAFTAR PUSTAKA}

[1]. Aprilius W, Augustino L, Yeremia OMH. Implementasi Algoritma MAX-MIN Ant System pada Penjadwalan Mata Kuliah. ULTIMATICS.2013: 5:49.

[2]. Karjono, Moedjiono, Kurniawan D. Ant Colony Optimization. Jurnal TICOM. 2016: 4:119-121.

[3]. Astuti RF, Satyahadewi N, Perdana H. Penyusunan Penjadwalan Ujian Menggunakan Algoritma Rank Based Ant System. Bimaster.2017: 6(2):152-153.

[4]. Stutzle T, Hoos HH. MAX-MIN Ant System. Future Generation Computer Systems. 2000:16 (8): 889-914.

[5]. Dorigo M, Birattari M, Stutzle T. Ant Colony Optimization. Computational Intelligence Magazine, IEEE. 1. 2006: 28-39.

$\begin{array}{lll}\text { QALBI ALIKLAS } & : & \begin{array}{l}\text { Jurusan Matematika FMIPA UNTAN, Pontianak } \\ \text { qalbialiklas@ student.untan.ac.id }\end{array} \\ \text { NEVA SATYAHADEWI } & : & \begin{array}{l}\text { Jurusan Matematika FMIPA UNTAN, Pontianak } \\ \text { neva.satya @ math.untan.ac.id }\end{array} \\ \text { HENDRA PERDANA } & : & \begin{array}{l}\text { Jurusan Matematika FMIPA UNTAN, Pontianak } \\ \text { hendra.perdana @math.untan.ac.id }\end{array}\end{array}$

